\title{
FRACTURE OF LIGHTWEIGHT FOAMED CONCRETE IN EVALUATION OF BOND BEHAVIOUR OF STEEL REINFORCEMENT EMBEDDED IN LWFC
}

\author{
JOHANNES P. DE VILLIERS ${ }^{*}$, GIDEON P.A.G. VAN ZIJL ${ }^{\dagger}$ AND ALGURNON S. VAN \\ ROOYEN ${ }^{\dagger \dagger}$
}

\author{
Civil Engineering Department, Stellenbosch University, South Africa

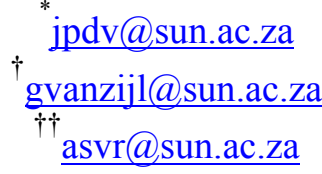

Key words: Lightweight Concrete, Foamed concrete, Bond, Fracture Energy

\begin{abstract}
Low weight, self-levelling, high workability and thermal insulating properties make lightweight foamed concrete (LWFC) an attractive substitute for normal weight concrete (NWC). The unfamiliarity of LWFC and paucity of design guidance pose concern for its use in structural application. One such concern is the bonding of steel reinforcement within LWFC. The bond behaviour of deformed steel reinforcement (rebar), embedded in LWFC and NWC was tested using pull-out (PO) and the beam-end (BE) tests ${ }^{[1]}$. The concretes used for testing were a reference NWC and LWFC with casting densities of 1200,1400 and $1600 \mathrm{~kg} / \mathrm{m}^{3}$. The nominal diameters of rebar used were Y10, Y12 and Y20 at embedded lengths of 3, 4 and 5 nominal bar diameters. Characterization of these materials included compressive strength, Young's modulus, tensile splitting strength and wedge splitting fracture energy.

The bond-slip envelopes of the denser LWFC yield significant bond stress magnitudes, but lack the ductility in failure observed in the NWC tests. The least dense LWFC exhibits ductility during failure, but lacks sufficient bonding stress magnitude. A significant difference in bond behaviour is observed between the results of the PO tests and the BE tests. The interaction of LWFC fracture and rebar bond mechanisms in the BE tests in the presence of shear and bending moment, is the direct cause, and the relatively low fracture toughness leads to low apparent bond resistance. Through this understanding, material improvement is envisaged by inclusion of aggregate to increase cracking tortuosity and thereby fracture energy of LWFC, in order to improve rebar bond in LWFC.
\end{abstract}

\section{INTRODUCTION}

Lightweight foamed concrete (LWFC) holds benefits of light structural weight and thermal properties superior to normal weight concrete (NWC). In this paper, non-heat treated LWFC is considered. Typically, LWFC has lower mechanical strength and stiffness than NWC, although advancements have been made especially in strength, achieving compressive strength classes suitable for structural application (Kearsley and Mostert, $2005^{[1]}$; Jones and McCarthy, 2005 ${ }^{[2]}$ ).

To extend the notion of structural use of LWFC by steel bar reinforcement, the bond between reinforcement and the matrix must be known. This bond does not only depend on the surrounding matrix, but also the reinforcement geometry (Sistonen et al., 2001 ${ }^{[3]}$; El Zareef and Schlaich, 2008 ${ }^{[4]}$; Desnerck and De Schutter, 2010 ${ }^{[5]}$; Farghal Maree and Hilal 
Riad, 2014 ${ }^{[6]}$ ). Bond mechanisms include chemical adhesion, friction and mechanical interlock. The cement paste adhesion to the steel is relatively small and typically ignored. Once adhesion is lost, slip of the reinforcement initiates. Transverse pressure due to confinement causes frictional resistance, typically considered to be proportional to the transverse pressure. Mechanical interlock occurs as a result of the steel ribs bearing on the matrix and causing crushing and wedging of the concrete between the ribs. This phase enhances the bond stress until the resulting circumferential stress becomes large enough for splitting failure at the free surface of the concrete to occur, or the bar pulls free from the concrete $^{[7]}$.

\section{LIGHT WEIGHT FOAMED CONCRETE}

At Stellenbosch University a research program is dedicated to development of LWFC for structural application, including appropriate improvement and characterisation of mechanical properties, as well as measures for durability. Lack of lightweight aggregate locally has ruled out development of light weight aggregate concrete. Mix design guidelines have been developed, and mix ingredient materials and typical proportions are given in Table 1. Also shown are the mechanical properties of compressive strength $\left(f_{c u}\right)$, Young's Modulus $\left(E_{\mathcal{C}}\right)$ and splitting tensile strength $(f t u)$. The coefficients of variation are shown in brackets. The properties were determined from standard tests at 28 days of water curing at $23 \pm 2^{\circ} \mathrm{C}$. Wedge splitting tests were performed to determine fracture energy $(G f)$. The length scale was calculated from:

$$
l_{c}=\frac{G_{f} E_{c}}{\left(f_{t}\right)^{2}}
$$

Relatively high compressive and tensile strength is achieved, but fracture energy and length scale are disproportionally low compared with NWC. This can be improved by materials development, e.g. by inclusion of fibre or coarse aggregate. This paper investigates the bond of reinforcing steel in LWFC with the properties in Table 1 through carefully executed pull-out (PO) and beam-end (BE) bond tests, while monitoring splitting crack formation and rate in the $\mathrm{BE}$ tests.

Table 1: LWFC mix compositions, also showing a typical NWC

\begin{tabular}{|c|c|c|c|c|}
\hline \multirow{2}{*}{$\begin{array}{l}\text { Target casting } \\
\text { density }\left[\mathrm{kg} / \mathrm{m}^{3}\right]\end{array}$} & $12 \mathrm{~F}$ & $14 \mathrm{~F}$ & $16 \mathrm{~F}$ & NWC \\
\hline & 1200 & 1400 & 1600 & 2366 \\
\hline CEM I-52.5 & 447.2 & 526.7 & 606.2 & 336.2 \\
\hline Fly-ash, Class S & 447.2 & 526.7 & 606.2 & 0 \\
\hline Coarse aggregate & 0 & 0 & 0 & 1000 \\
\hline Sand & 0 & 0 & 0 & 835 \\
\hline Water & 277.3 & 326.6 & 375.9 & 195 \\
\hline Foam [Litre] & 377.0 & 266.3 & 155.5 & 0 \\
\hline$f_{c u}[\mathrm{MPa}]$ (cube) & $\begin{array}{c}10.41 \\
(0.057)\end{array}$ & $\begin{array}{c}19.1 \\
(0.053)\end{array}$ & $\begin{array}{c}32.26 \\
(0.105)\end{array}$ & $\begin{array}{c}38.66 \\
(0.038)\end{array}$ \\
\hline$E_{c}[\mathrm{GPa}]$ & $\begin{array}{c}6.46 \\
(0.030)\end{array}$ & $\begin{array}{c}8.75 \\
(0.001)\end{array}$ & $\begin{array}{c}12.15 \\
(0.022)\end{array}$ & $\begin{array}{c}31.48 \\
(0.114)\end{array}$ \\
\hline$f_{t}[\mathrm{MPa}]$ & $\begin{array}{c}1.31 \\
(0.061) \\
\end{array}$ & $\begin{array}{c}2.14 \\
(0.062) \\
\end{array}$ & $\begin{array}{c}3.63 \\
(0.092) \\
\end{array}$ & $\begin{array}{c}4.15 \\
(0.017) \\
\end{array}$ \\
\hline$G f[\mathrm{~N} / \mathrm{m}]$ & 4.67 & 5.72 & 7.32 & 123.55 \\
\hline$l_{c}[\mathrm{~mm}]$ & 15.42 & 11.06 & 6.75 & 938 \\
\hline
\end{tabular}

\section{BOND TESTS}

Two bond test procedures were performed; a simple direct pull-out test according to ASTM C234 (withdrawn), and beam end tests $^{[8]}$. Steel bars from a single batch complying with South African standards (SABS 920) ${ }^{[9]}$ were used. Three bar diameters, $10 \mathrm{~mm}$ (denoted Y10), $12 \mathrm{~mm}$ (Y12) and 20 $\mathrm{mm}$ (Y20) were used in the test series. The Ysteel bar geometry is described in Fig. 1 and Table 2.

\subsection{Pull-out tests}

PO tests were conducted according to ASTM C234. The standard has been withdrawn, but was nevertheless used as a comparative test. The specimen is a $150 \mathrm{~mm}$ cube, with the steel bar centrally embedded as shown in Fig. 2. Test variables were density $(12 \mathrm{~F}, 14 \mathrm{~F}, 16 \mathrm{~F}, \mathrm{NWC})$, bar diameter (Y10, Y12, Y20) and embedded length $(3 \varphi, 4 \varphi$ and $5 \varphi$, with $\varphi$ the nominal bar diameter).

The test was performed in a Contest Z250 Materials testing machine (MTM) at a MTM displacement rate of $0.1 \mathrm{~mm} / \mathrm{s}$ of the loaded- 
end slip. An LVDT measured the free-end displacement of the rebar as shown in Fig. 2 (right). The LVDT tip was securely positioned in a slot drilled into the free-end of the rebar.

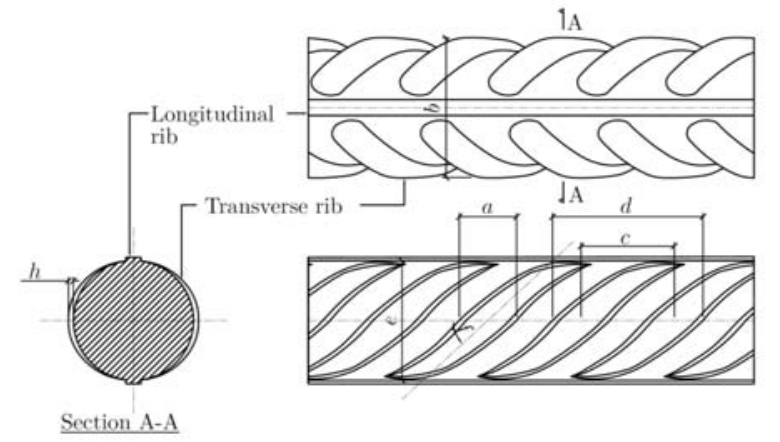

Figure 1: (a) Pull-out and (b) Beam-end bond test.

Table 2. Average engineering properties of LWFC and NWC, with coefficient of variation in brackets.

\begin{tabular}{cccc}
\hline Property & Y20 & Y12 & Y10 \\
\hline$a[\mathrm{~mm}]$ & 6.14 & 3.29 & 2.38 \\
\hline$b[\mathrm{~mm}]$ & 22.48 & 12.63 & 10.24 \\
\hline$c[\mathrm{~mm}]$ & 15.87 & 6.77 & 6.42 \\
\hline$d[\mathrm{~mm}]$ & 22.01 & 10.07 & 8.80 \\
\hline$e[\mathrm{~mm}]$ & 18.28 & 11.61 & 9.60 \\
\hline
\end{tabular}

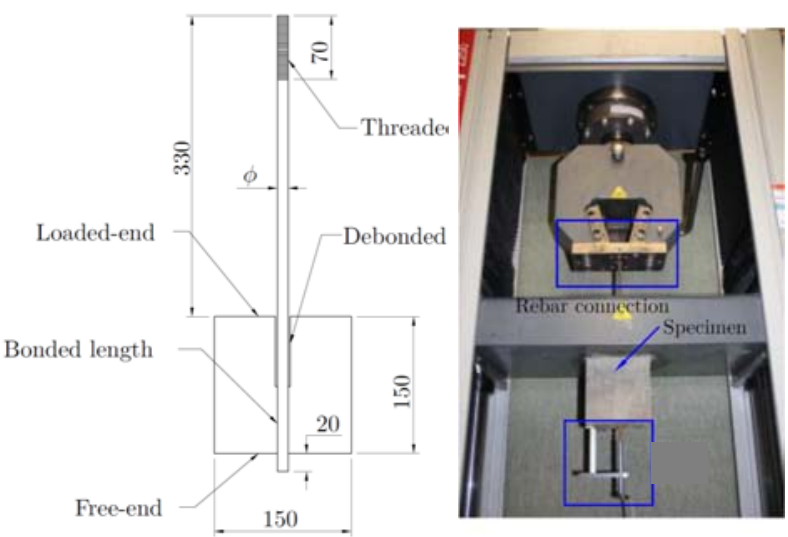

Figure 2: Pull-out test specimen and setup in Zwick Z250 MTM.

\subsection{Beam-end bond tests}

BE tests were performed according to [9]. This test simulates the conditions in a beam more directly, and the bonded region of the reinforcement bar is in a constant shear force region and a bending moment, unlike in the PO test where the concrete cube is in compression. The specimen geometry and setup is shown in Fig. 3.

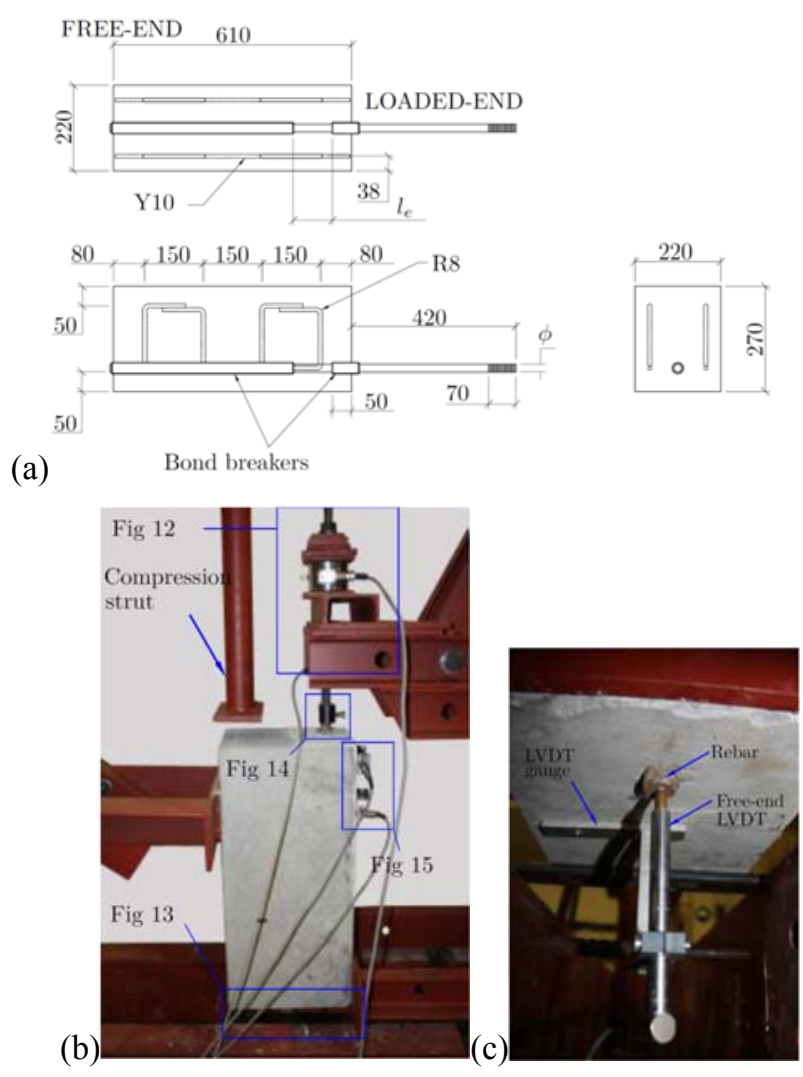

Figure 3: Beam-end bond test (a) specimen, (b) setup in a custom-built frame and (c) LVDT measuring the steel bar lower (free) end slip.

Stirrups bent from smooth $8 \mathrm{~mm}$ diameter steel bars were included to prevent shear failure. As shown in Fig. 3a (right), they were placed in a manner that does not provide confinement to the tension bar. Additional Y10 steel bars were also placed and fully embedded alongside the test bar to ensure sufficient bending resistance.

The test variables were density $(12 \mathrm{~F}, 14 \mathrm{~F}, 16 \mathrm{~F}$, NWC), bar diameter (Y12 and Y20), but a single embedded length of $5 \varphi$.

The BE specimen was altered from ASTM A944-10 (2002), which specifies that the bonded, embedded length be provided from the loaded-end, after which a bond breaker is installed $115 \mathrm{~mm}$ down towards the free-end. This implies a fully bonded region at the top end of the specimen. This arrangement will influence the free-end LVDT slip reading, which, for the methodology of this investigation, is considered a critical measurement. This was modified to have a 
bonded region $50 \mathrm{~mm}$ from the upper face (see Fig. 3a. Such alteration was also implemented by Farghal Maree and Hilal Riad (2014) ${ }^{[6]}$. However, they positioned the embedded length next to the bearing area of a lateral column support (Fig. 3b). For this investigation the embedded length was provided closer to the loaded-end, sufficiently removed from the lateral strut bearing position and into the bonding moment region to simulate bond in a structural $\mathrm{RC}$ member. The bonded region was offset by $50 \mathrm{~mm}$ from the loaded-end concrete face, following Soltani et al. $(2003)^{[10]}$.

The BE tests were performed in a $500 \mathrm{kN}$ Instron MTM. The steel rebar was fixed through a load cell to the horizontal support on the right side of the test loading rig. A $200 \mathrm{kN}$ load cell was used to measure the axial force in the reinforcing bar. Fig. $3 \mathrm{c}$ shows the LVDT for free-end slip measurement. Similarly, an LVDT was fixed to the loaded-end of the rebar, $50 \mathrm{~mm}$ above the top concrete face. This measurement was used for the displacementcontrolled test.

To monitor splitting cracking in the BE specimens, two LVDTs were attached to each specimen as shown in Fig. 4. The top LVDT was attached at the upper edge of the embedded length, and the other at the lower edge.
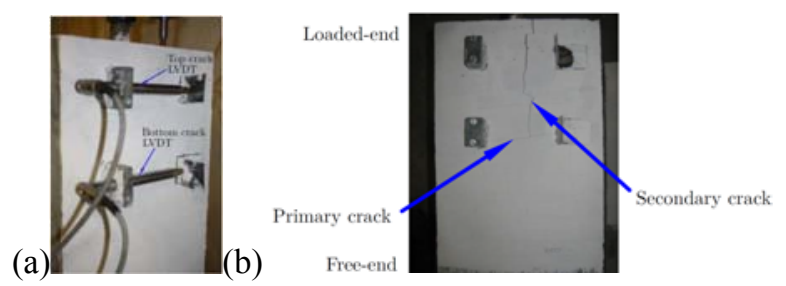

Figure 4: Splitting crack (a) LVDT arrangement for measurement and (b) visible in the 16F-B-20-5 specimen.

\section{BOND TEST RESULTS}

The methods used for the determination of a design bond stress in design standards such as BS EN 1992-1-1 (2004) ${ }^{[11]}$ and SABS 0100-1 (2000 ${ }^{[12]}$, are unknown to the authors. Leonhardt $(1977)^{[13]}$ proposed taking the design bond stress $\sigma_{d}$ as the average bond stress when the bar has a free-end slip of
$0.1 \mathrm{~mm}$, i.e. at the design slip $S_{d}$. This could be related to the typical crack width limitation in $\mathrm{RC}$ of $0.1 \mathrm{~mm}$. In the results that follow, the resistance at a free-end slip of $0.1 \mathrm{~mm}$ has been used for calculation of bond resistance.

\subsection{Pull-out bond test results}

In Fig. 5 the bond stress-slip responses for NWC with Y10 and Y20 bars are shown. The slip up to $0.2 \mathrm{~mm}$ is shown on a different scale to illuminate the behaviour in this regime. It is evident that the bond stress, which is considered to be uniform along the bonded length, is inversely proportional to the bond lengths used here $(3 \varphi, 4 \varphi$ and $5 \varphi)$. Also shown in Fig. 5 is the MC2010 ${ }^{[14]}$ model response for these specimen parameters, which forms a lower boundary for the measured responses. For all NWC specimens with Y10 and Y12 bars pull-out failure dominated, but for Y20 specimens, the ultimate failure, beyond the 0.1 $\mathrm{mm}$ free-end slip threshold, was caused by splitting.

The responses for PO bond stress versus bar slip results are shown in Fig. 6 for one third of the specimens, i.e. all specimens with embedded lengths of $4 \varphi$. Pull-out failure dominated for all F12 specimens, and for all F14 specimens with the exception of the large diameter (Y20) bar at the longest embedded length $(5 \varphi)$, which failed once a splitting crack formed. All the F16 specimens failed by splitting. Note that in only the F16-P-20 specimens, i.e. the F16 with large bar diameter (Y20) at $3 \varphi, 4 \varphi$ and $5 \varphi$ embedded lengths, splitting failure occurred before the $0.1 \mathrm{~mm}$ slip was reached. In all other cases, splitting failure occurred after this threshold slip level. 

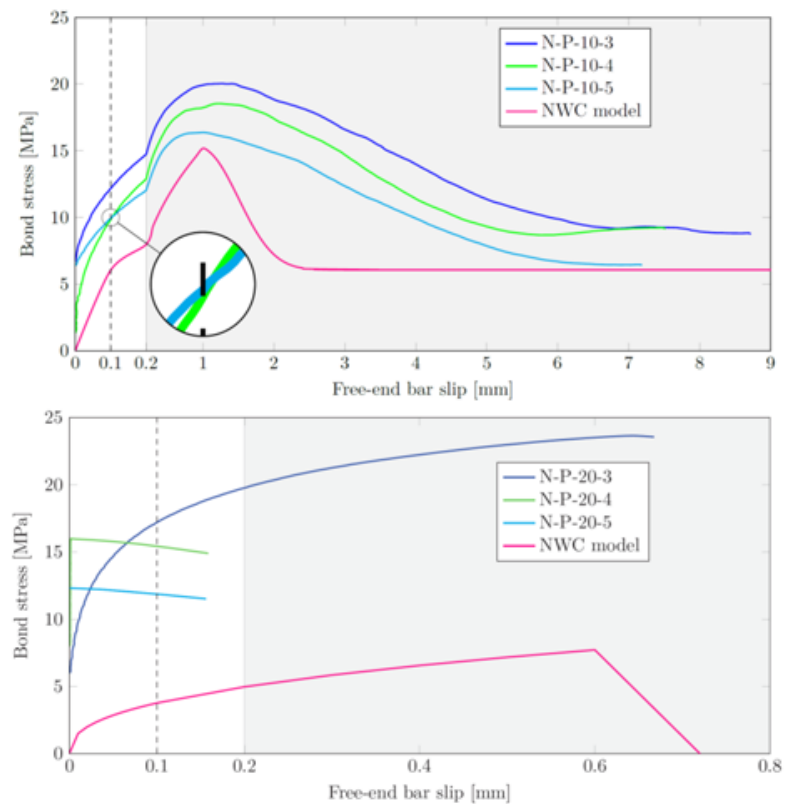

Figure 5: Pull-out test results for NWC.

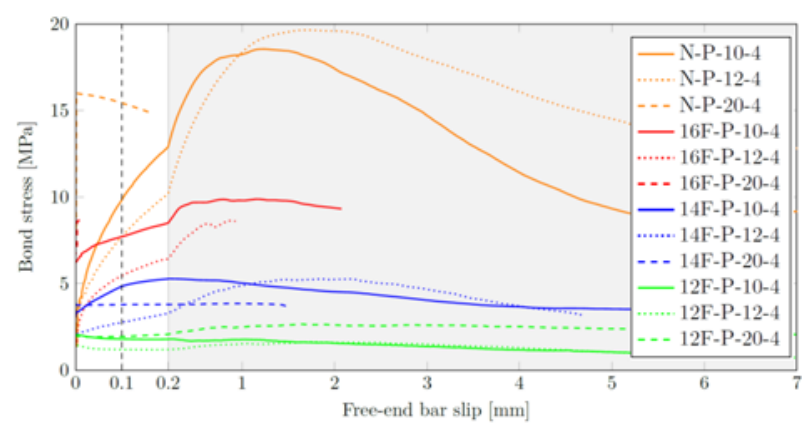

Figure 6: Pull-out test results for LWFC with $4 \varphi$ embedded length

\subsection{Beam-end bond test results}

The bond stress-slip responses of the $\mathrm{BE}$ specimens are shown in Fig. 7. It is evident that all specimens reached the $0.1 \mathrm{~mm}$ threshold free-end slip, and beyond. In the Y12 bar specimens, pull-out failure occurred. In all the Y20 specimens, splitting cracks arose and were recorded by the LVDTs shown in Fig. 4.

Fig. 8 shows these recorded measurements for the Y20 bar specimens in all three density classes $(12 \mathrm{~F}, 14 \mathrm{~F} 16 \mathrm{~F})$. The deformations recorded by these LVDTs are largely attributed to the crack itself due to low elastic deformation in the measurement region of the LVDTs. The bar slip at which the splitting crack reaches the surface, is smaller with increasing LWFC density. In the 12F specimen the surface crack initiates at roughly
$0.6 \mathrm{~mm}$ slip, well beyond the $0.1 \mathrm{~mm}$ threshold slip considered for the bond stress. In $14 \mathrm{~F}$ and $16 \mathrm{~F}$ it initiates at about $0.03 \mathrm{~mm}$.
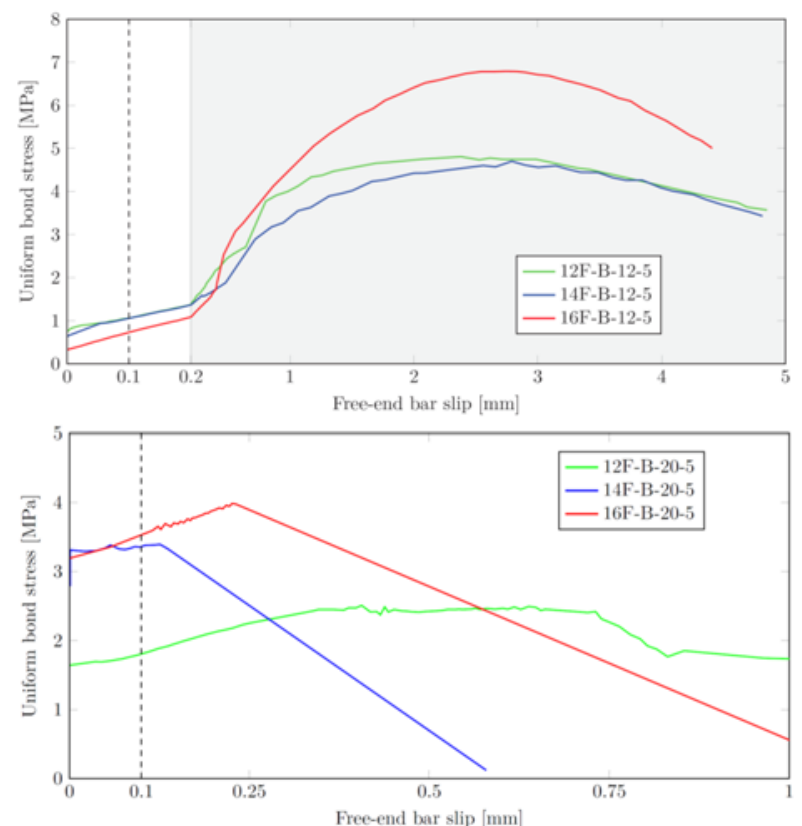

Figure 7: BE test results for the $12 \mathrm{~mm}$ bar (top) and $20 \mathrm{~mm}$ bar (bottom).
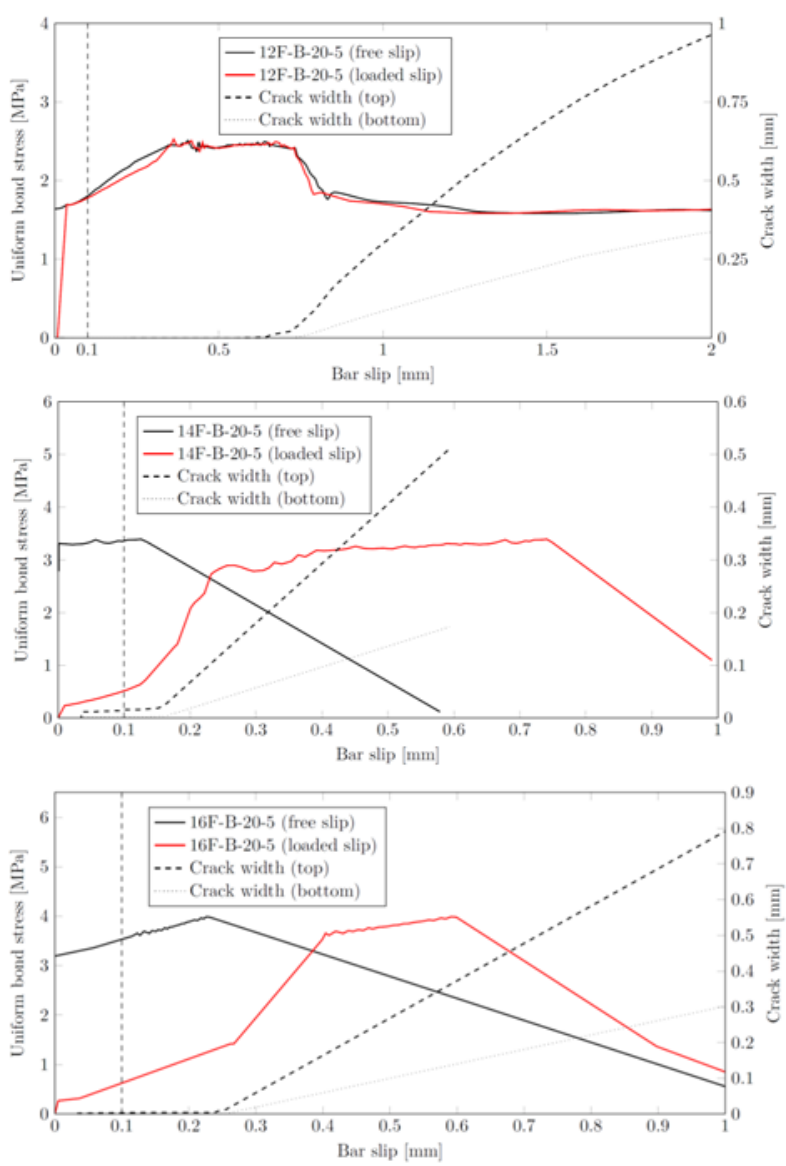

Figure 8: Beam-end test results for the B-20-5 series, showing splitting crack measurements. 
The slip at which the splitting crack starts to widen also marks the onset of reduced bond resistance. From these recorded measurements, the crack widening rate in this phase of the response could be calculated. In the $12 \mathrm{~F}$ specimen, the splitting crack widening rate at the top gauge area was $0.00033 \mathrm{~mm} / \mathrm{s}$, but for the $14 \mathrm{~F}$ and $16 \mathrm{~F}$ specimens much higher rates of $1.335 \mathrm{~mm} / \mathrm{s}$ and $2.18 \mathrm{~mm} / \mathrm{s}$ were recorded.

\subsection{Comparison: PO vs BE bond stress}

The design bond stress $\left(\sigma_{d}\right)$ as determined from the $\mathrm{PO}$ and $\mathrm{BE}$ tests for the resistance at a free-end slip of $0.1 \mathrm{~mm}$, are summarised in Table 3 . Note that the $3 \varphi, 4 \varphi$ and $5 \varphi$ results for the PO tests are averaged in the table, in order to compare them with the single embedded length of $5 \varphi$ used in the BE tests. It is evident that the $\mathrm{BE}$ values are in all cases lower than those from the PO tests.

In Fig. 9, the design bond stresses are compared with standardised values ${ }^{[11,12]}$. The solid and dashed lines connect the LWFC bond stresses obtained from the $\mathrm{PO}$ and $\mathrm{BE}$ results respectively. The comparison is done based on the cube compressive strengths (Table 1).

Table 2. Average engineering properties of LWFC and NWC, with coefficient of variation in brackets.

\begin{tabular}{cccc}
\hline Concrete & \multicolumn{2}{c}{ Bar } & \multicolumn{2}{c}{$\sigma_{d}[\mathrm{MPa}]$} \\
\cline { 2 - 4 } & $\mathbf{Y}$ & $\mathrm{PO}$ & $\mathrm{BE}$ \\
\hline \multirow{2}{*}{$12 \mathrm{~F}$} & 10 & 1.89 & - \\
\cline { 2 - 4 } & 12 & 1.59 & 1.06 \\
\cline { 2 - 4 } & 20 & 1.94 & 1.80 \\
\hline \multirow{2}{*}{$14 \mathrm{~F}$} & 10 & 0.94 & - \\
& 12 & 4.27 & 1.05 \\
\cline { 2 - 4 } & 20 & 4.74 & 3.36 \\
\hline \multirow{2}{*}{$16 \mathrm{~F}$} & 10 & 1.20 & - \\
\hline & 12 & 6.01 & 0.72 \\
\hline \multirow{2}{*}{$\mathrm{NWC}$} & 20 & 8.34 & 3.53 \\
\hline & 10 & 1.76 & - \\
\hline & 12 & 9.21 & 6.00 \\
\hline & 20 & 15.18 & 11.81 \\
\hline
\end{tabular}

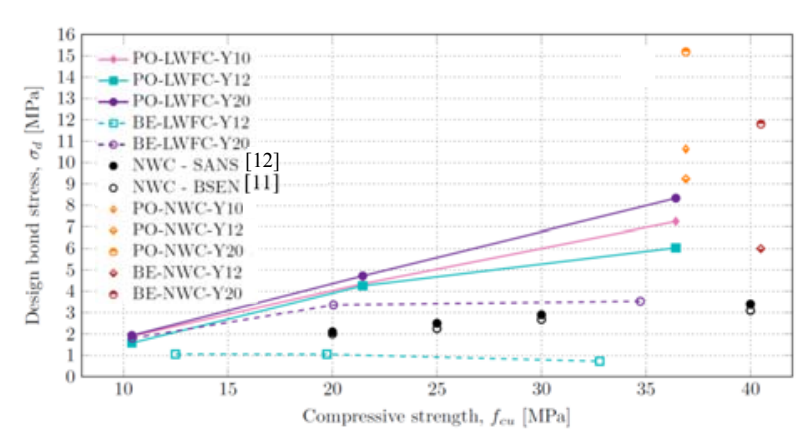

Figure 9: Comparison of all bond stress results with standardised design values ${ }^{[11,12]}$.

\section{TOWARDS IMPROVED BOND}

Different stress states occur in the PO and $\mathrm{BE}$ tests, which contribute to the differences in bond-slip response obtained from these two tests. While splitting cracks arose in PO tests for the higher density LWFC and especially for the larger bar diameter, this was not recorded during the test as was done in the case of the BE tests (Fig. 8). More representative stress fields arise in the $\mathrm{BE}$ tests, including transverse shear stresses and bending stresses, as was evident from bending cracks (Fig. 4b).

Investigating the mechanical properties of the LWFC considered here further, a normalised graph of the main strength, stiffness and fracture energy parameters (from Table 1), but also showing the design bond strength as function of density, is given in Fig. 10. In the top graph of Fig. 10, these parameters are shown for the PO tests, while the lower graph shows the same for the $\mathrm{BE}$ tests. It is clear that, while disproportionate high compressive and tensile strength has been achieved with materials development of the LWFC, the Young's Modulus, but especially the fracture energy (and length scale) are disproportionately low for the LWFC. From the graphs, it appears that the bond stress, as defined here, largely follows the strength (compressive and tensile) - density relation. However, the BE bond stresses follow the fracture energy and length scale.

Materials improvement of the LWFC is recommended. In current work, inclusion of fibres and coarse aggregate is investigated, in order to increase fracture energy, and thereby bond in LWFC. 

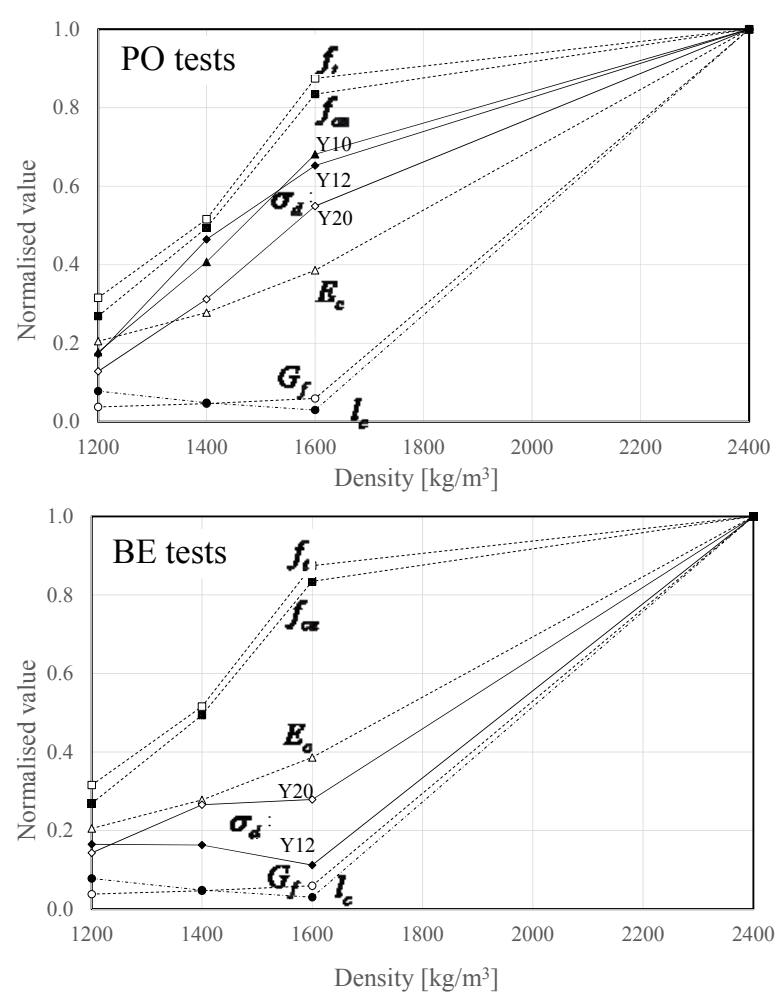

Figure 10: Normalised mechanical properties and design bond stress obtained from PO and BE tests.

\section{CONCLUSION}

Bond of steel reinforcing bars in LWFC was investigated with pull-out and beam-end tests, and compared with a reference NWC, as well as standardised bond stresses in Eurocode $^{[11]}$ and SANS ${ }^{[12]}$. From the experimental investigation, the following conclusions are drawn:

- Lower design bond stress magnitudes are achieved in PO than BE

- Fracture energy appears to dominate BE bond stress whilst PO seems to be dominated by compressive strength

- Likelihood of splitting failure increases with increasing density, rebar diameter, and embedment length.

\section{REFERENCES}

[1] ASTM A944-10 2002. Comparing Bond Strength of Steel Reinforcing Bars to Concrete Using Beam-End Specimens. ASTM International. Pennsylvania, USA.

[1] Kearsley, E.P. and Mostert, H.F. 2005. "Designing mix composition of foamed concrete with high fly ash contents". In: Proc., Int. Conf. on the Use of Foamed Concrete in Construction. Thomas Telford, London, pp. 29-36.

[2] Jones, M.R. and McCarthy, A. 2005. "Preliminary views on the potential of foamed concrete as a structural material". In: Magazine of Concrete Research 57.1, pp. 21-31. [1] Griffith, A. A. 1924. Theory of rupture. In Biezeno, C.B. and Burgers, J.M. (Eds) Proceedings of $1 s t$ International Congress of Applied Mechanics; pp. 55-63.

[3] Sistonen, E., Tulkiainen, P., and Huovinen, S.: Bonding of hot dip galvanised reinforcement in concrete. url: https://www.tekna.no/ikbViewer/Content /225411/F40\%20-\%20Sistonen\%20\%202005-09-02\%20FINAL.pdf (accessed on 06/18/2014).

[4] El Zareef, M. and Schlaich, M.: Bond behaviour between GFR bars and infralightweight concrete, Tailor Made Concrete Structures, 2008, pp. 721-727.

[5] Desnerck, P. and De Schutter, G.: Bond behaviour of reinforcing bars in self-compacting concrete: experimental determination by using beam tests, Materials and Structures 2010,43, pp. 53-62.

[6] Farghal Maree, A. and Hilal Riad, K.: Analytical and experimental investigation for bond behaviour of newly developed polystyrene foam particles' lightweight concrete, Engineering Structures, 2014, 58.1, pp. 1-11.

[7] Penelis, George G. andPenelis, Gregory, G.: Concrete Buildings in Seismic Regions, CRCPress - Taylor \& Francis Group, 2014.

[8] ASTM A944-10: Comparing Bond Strength of Steel Reinforcing Bars to Concrete Using Beam-End specimens. ASTM International. Pennsylvania, USA, 2002.

[9] SABS 920. Steel bars for concrete reinforcement. The South African Bureau of Standards, South Africa, 2011.

[10] Soltani, Masoud, An, Xuehui, and Maekawa, Koichi: Computational model for post cracking analysis of RC membrane elements based on local stress-strain characteristics, Engineering 
Structures, 2003, 25.8, pp. 993-1007.

[11]BS EN 1992-1-1: Eurocode 2: Design of concrete structures Part 1-1: General rules and rules for buildings. British Standards Institution. London, 2004.

[12]SABS 0100-1: The structural use of concrete, Part 1: Design. The South African Bureau of Standards, South Africa, 2000.

[13]Leonhardt, F. Vorlesungen über Massivbau: Teil 3: Grundlagen zum Bewehren im Stahlbetonbau. Vorlesungen über Massivbau, Springer-Verlag GmbH. ISBN $9783540081210,1977$.

[14] Model Code 2010. FIB special activity group 5. 